\title{
Contribution to the Study of the Formation Mechanism of Ordered Porous Carbons from a Soft-Template Method using the Copolymer Triblock $\left(\mathrm{PEO}_{140} \mathbf{P P O}_{39} \mathbf{P E O}_{140}\right)$ and a Phenolic Resin
}

\author{
Cristiam F. Santa and Ligia Sierra* \\ Grupo Ciencias de los Materiales, Sede de Investigaciones Universitarias (SIU), \\ Universidad de Antioquia, Calle 62 No. 52-59, lab 310, PA1226, Medellín, Colombia
}

\begin{abstract}
Diferentes carbonos porosos foram sintetizados empregando automontagem direta de um surfactante non-iônico $\left(\mathrm{PEO}_{140} \mathrm{PPO}_{39} \mathrm{PEO}_{140}\left(\right.\right.$ Pluronic $\left.^{\circledR}\right)$, PEO poli(óxido de etileno) e PPO poli(óxido de propileno)) e uma resina fenólica. Segundo experimentos de espalhamento de luz dinâmico (DLS) realizados antes da floculação, a formação de micelas híbridas cobertas (precursores de materiais mesoporosos ordenados) compete com a formação de partículas resol dependendo da concentração do surfactante. Elevada temperatura de síntese aumenta a formação de mesoporosidade. Quando monômeros (ao invés de oligômeros) são usados como precursores de resina, a mesoporosidade também é aumentada. Porém neste caso, a formação de partículas resol também é favorecida. Os materiais obtidos são principalmente microporosos, indicando que polímeros/micelas híbridas surfactantes não são estáveis o suficiente para modelar a formação de carbonos altamente mesoporosos. A interação apropriada entre micelas surfactantes e espécies precursoras de resinas, assim como o grau de polimerização da resina, é crucial para a obtenção de polímeros/micelas híbridas surfactantes que conduzam à formação de carbonos mesoporosos.
\end{abstract}

Different porous carbons were synthesized using direct self-assembly of a nonionic surfactant $\left(\mathrm{PEO}_{140} \mathrm{PPO}_{39} \mathrm{PEO}_{140}, \mathrm{PEO}\right.$ poly(ethylene oxide) and $\mathrm{PPO}$ poly(propylene oxide)) and a phenolic resin. According to dynamic light scattering (DLS) experiments realized before the flocculation, the formation of covered hybrid micelles (precursors of ordered mesoporous materials) competes with the formation of resol particles depending on the surfactant concentration. High synthesis temperature increases the formation of mesoporosity. When monomers (instead of oligomers) are used as resin precursors, the mesoporosity is also enhanced. However in this case, the formation of resol particles is also favored. The obtained materials are mainly microporous, indicating that the formed polymer/surfactant hybrid micelles are not stable enough to template the formation of highly mesoporous carbons. Appropriate interaction between the surfactant micelles and resin precursor species, as well as the polymerization degree of the resin, is crucial for obtaining polymer/ surfactant hybrid micelles that conduce to mesoporous carbons.

Keywords: dynamic light scattering (DLS), porous carbons by surfactant templating, polymer particle formation

\section{Introduction}

Mesoporous materials have been extensively studied during the last two decades due to their potential applications in several research fields such as catalysis, ${ }^{1}$ separation processes ${ }^{2}$ and electrochemistry. ${ }^{3}$ Among these materials, ordered mesoporous silicas obtained by the use of a surfactant self-assembled nanostructure (soft-template method) as template have been the most studied. ${ }^{4}$ There

*e-mail: ligia.sierra@gmail.com has been established several synthetic strategies that allow the control of their pore size, morphology, specific surface area and pore volume. The extrapolation of these strategies to the synthesis of mesoporous carbons has also been reported in the last decade, such as the evaporationinduced self-assembly (EISA) method and the aqueous surfactant assembly or hydrothermal approach..$^{5-9}$ In these methods, nonionic Pluronic ${ }^{\circledR}$ type surfactants are used as pore templates and phenolic resins as carbon precursors with their polymerization carried out in an organic solvent phase or in an aqueous acid or alkaline medium. By 
controlling the surfactant $\mathrm{PEO} / \mathrm{PPO}$ (PEO poly(ethylene oxide) and $\mathrm{PPO}$ poly(propylene oxide)) length ratio and the phenol/template molar ratio, several pore morphologies have been obtained. ${ }^{10}$

The use of the dynamic light scattering (DLS) technique for studying the formation mechanism of mesoporous materials (in special for the synthesis of mesoporous silicas) has been reported. ${ }^{11-13}$ DLS studies in the evolution of the species present in the SBA-15 and SBA-16 silica syntheses revealed important features of their formation mechanism. ${ }^{12}$ These DLS results showed the presence of micelles around $10-30 \mathrm{~nm}$ in the first stage of the synthesis. During this stage (before flocculation) deposition of siliceous species upon the micelle corona takes place, keeping the micelle size approximately constant but increasing their scattered light intensity. Then, the moment of the phase separation or flocculation (destabilization and colloidal aggregation) is detected by the appearance of larger species corresponding to micron sized liquid hybrid particles, which transform into solid particles during the aging step.

Mesoporous carbons have been obtained not only by template approaches, but also modulating the textural porosity produced by the aggregation of resin nanoparticles. Scherdel et al. ${ }^{14}$ synthesized highly mesoporous carbons based on the resorcinol-formaldehyde polymerization, without using surfactants. The controls of the monomers/catalyst mass ratio and the concentration of the monomers, which affects the polymerization rate, are crucial to obtain nanoparticle aggregates instead of polymeric monoliths. With a low ratio, therefore a high polymerization rate, monolithic morphology is obtained. The presence of the surfactant in the synthesis of porous carbons by a soft-template method can adjust the polymerization to obtain resin nanoparticles instead of monolithic materials.

The aim of this work was to study if the formation mechanism of SBA-16 mesoporous silica particles, which were synthesized with the triblock copolymer $\mathrm{PEO}_{140} \mathrm{PPO}_{39} \mathrm{PEO}_{140}$ as template, ${ }^{13}$ also applies for mesoporous carbons. These ones synthesized by an aqueous method with this surfactant and a phenolic resin polymerized in alkaline aqueous medium as carbon precursor. DLS was used to follow in situ the behavior of the species present in the aqueous reaction mixtures from the earliest reaction stage until the formation of the particles.

\section{Experimental}

\section{Chemicals}

All chemicals were used as received. The triblock copolymer Pluronic $^{\circledR}$ (from now called "S14600")
$\mathrm{PEO}_{140} \mathrm{PPO}_{39} \mathrm{PEO}_{140}$ (84 wt.\% PEO $\mathrm{M}_{\mathrm{W}}=14600$ ) was purchased from Sigma-Aldrich Chemical Co. A commercial formaldehyde solution $(37 \%)$ was used. Sodium hydroxide and phenol were purchased from Merck and Co. Millipore filtered water was used in all experiments.

\section{Synthesis of porous carbons}

In a typical synthesis, an aqueous solution of S14600 surfactant was prepared and heated at $35{ }^{\circ} \mathrm{C}$ in an oil bath with magnetic stirring. In a separated flask, a mixture of formaldehyde, phenol and a $\mathrm{NaOH}$ solution $\left(0.1 \mathrm{~mol} \mathrm{~L}^{-1}\right)$ was prepared in a molar ratio of HCHO: $\phi-\mathrm{OH}: \mathrm{NaOH}$ (293:60:15). This mixture was prepolymerized by heating in an oil bath at $70{ }^{\circ} \mathrm{C}$ for $30 \mathrm{~min}$, under magnetic stirring. During this time, the solution color changed from translucent to light pink due to the formation of resin oligomers. Then, this solution was cooled to $35^{\circ} \mathrm{C}$ and mixed with the S14600 solution. The resultant mixture with a molar ratio composition S14600:HCHO: $\phi-\mathrm{OH}: \mathrm{NaOH}: \mathrm{H}_{2} \mathrm{O}$ of $\mathrm{x}: 293: 60: 15: 16900$ (with $\mathrm{x}$ varying between 0 and 1 ) and $\mathrm{pH} 9.4$ was first heated at $65^{\circ} \mathrm{C}$ (under magnetic stirring) for $1 \mathrm{~h}$ and after in an oven at the desired polymerization temperature $\left(60\right.$ or $\left.80^{\circ} \mathrm{C}\right)$ for $90 \mathrm{~h}$. At this time, the solution turned dark red and a solid with particle morphology was recovered by centrifugation. After washing and drying at room temperature over night, the solid was carbonized at $500{ }^{\circ} \mathrm{C}$ for $3 \mathrm{~h}$ in a horizontal tubular furnace under $\mathrm{N}_{2}$ atmosphere with flow rate of $100 \mathrm{~cm}^{3} \mathrm{~min}^{-1}$ and heating rate of $2{ }^{\circ} \mathrm{C} \mathrm{min}^{-1}$ from 25 to $500{ }^{\circ} \mathrm{C}$.

To evaluate the effect of mixing the surfactant solution with the resol precursors without having the prepolymerization step on the properties of the resultant polymer, a material was prepared at $80^{\circ} \mathrm{C}$ with the above procedure excepting this step, with a $\mathrm{S} 14600: \mathrm{NaOH}: \mathrm{H}_{2} \mathrm{O}$ molar ratio of 1:15:16900. The five synthesized materials with their specific synthesis parameters and nomenclatures are described in Table 1.

\section{Measurements}

Dynamic light scattering experiments (DLS) were carried out in the first step of the synthesis of C60S0, C60SB and C60SA materials in a DLS particle size analyzer with built in viscometer Horiba LB-550. This step involves the reaction evolution at $60^{\circ} \mathrm{C}$ of the alkaline mixture, which was formed by the monomers and surfactant solutions at $35^{\circ} \mathrm{C}$, until the phase separation occurs. For following this evolution, DLS measurements were made for samples taken from the reaction mixtures at $60{ }^{\circ} \mathrm{C}$ at different synthesis times until the phase separation is observed. 
Table 1. Parameters used in the synthesis of carbon materials

\begin{tabular}{lccc}
\hline Material name & Polymerization temperature $/{ }^{\circ} \mathrm{C}$ & $\mathrm{S} 14600: \mathrm{NaOH}: \mathrm{H}_{2} \mathrm{O}$ (molar ratio) & Prepolymerization step \\
\hline C60S0 & 60 & $0.00: 15: 16900$ & yes \\
C60SB & 60 & $0.33: 15: 16900$ & yes \\
C60SA & 60 & $1.00: 15: 16900$ & yes \\
C80SA & 80 & $1.00: 15: 16900$ & yes \\
C80SA-NP & 80 & $1.00: 15: 16900$ & no \\
\hline
\end{tabular}

The porous and thermal characteristics of the materials were studied by $\mathrm{N}_{2}$ sorption (Micromeritics ASAP2010) at $77 \mathrm{~K}$ and thermo gravimetric analysis (TGA) in air from 25 to $800^{\circ} \mathrm{C}$ at a heating rate of $10^{\circ} \mathrm{C} \mathrm{min}^{-1}$ (TA instruments TGA Q500). The materials before carbonization were characterized by Fourier transform infrared (FTIR) (Perkín Elmer Spectrum one, DTGS detector, eight scans by spectrum) and also by TGA technique. These materials are named R60S0 R60SA, R60SB and so on. The morphology of the carbon materials was studied by scanning electron microscopy (SEM) (JEOL, JSM 6490LV 20 kV).

\section{Results and Discussion}

\section{Surfactant concentration effect}

DLS Monitoring of the first step of the synthesis of C60SO, C60SB and C60SA

The behaviors of the species present in the first step of the synthesis of C60S0, C60SB and C60SA materials, followed by DLS, are shown in Figures 1 and 2. C60SB and C60SA materials present a hydrodynamic diameter (Dh) evolution like that reported for the synthesis of SBA-15 and SBA-16 mesoporous silicas. ${ }^{12}$ During the first stage, the Dh remains nearly constant, with a value close to that exhibited by the micelles $c a .10 \mathrm{~nm}$ (Dh value at 0 min measured before the addition of monomers), and there is an increase in the scattered light intensity, indicating a covering of the micelles. Then, it is seen an abrupt change in the Dh of the species. This is an indicative of the destabilization process of the colloidal system caused by the colloidal aggregation, which leads to the formation of larger species. ${ }^{12}$

The phase separation or flocculation of the colloid species occurs at 1200-1300 min for the C60SB material and at longer time ( $c a .3000 \mathrm{~min}$ ) for the C60SA material. Since the number of micelles present in the synthesis of C60SB material is lower than in the synthesis of C60SA material, the covering of the micelles needed to destabilize them is reached at shorter times.

In C60S0 synthesis, in which there were not micelles, resin particles ${ }^{14}$ of $c a .5 \mu \mathrm{m}$ size are present at $1590 \mathrm{~min}$, and
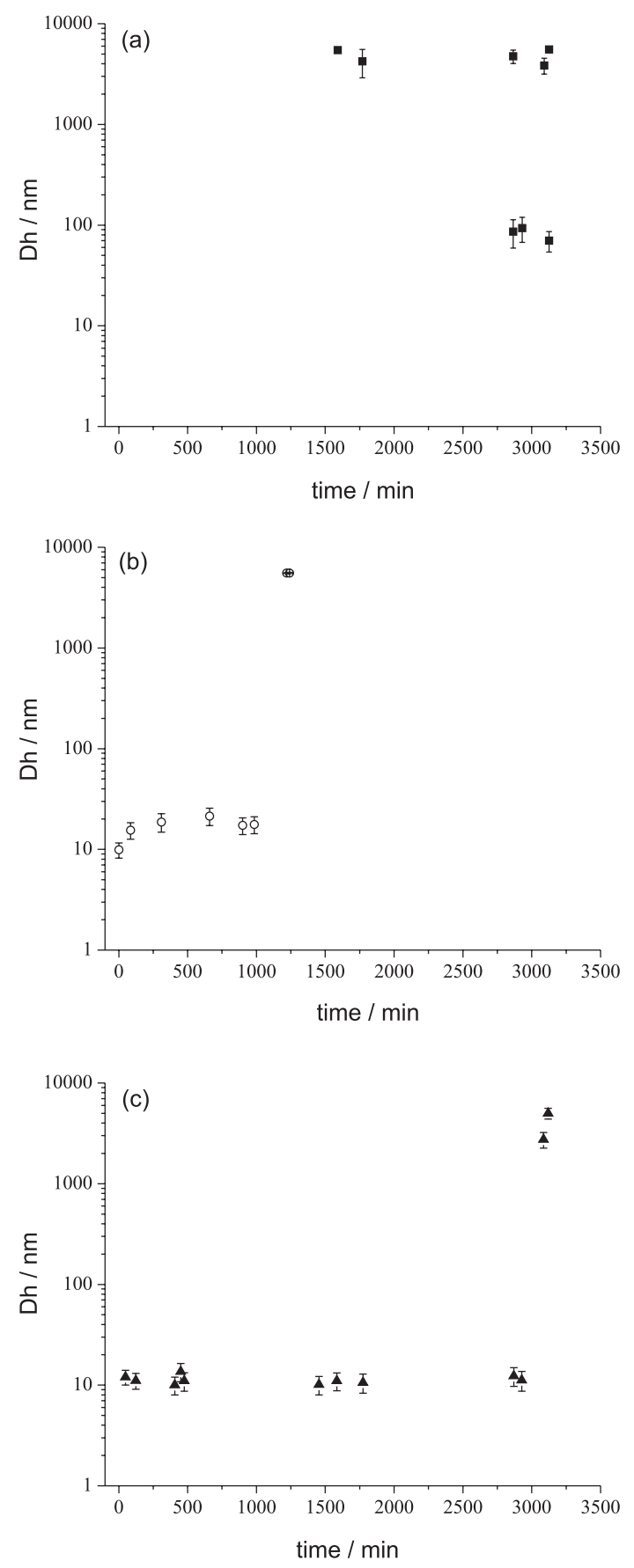

Figure 1. Evolution of the hydrodynamic diameter $(\mathrm{Dh})$ with time during the first synthesis step of (a) C60S0, (b) C60SB and (c) C60SA. 

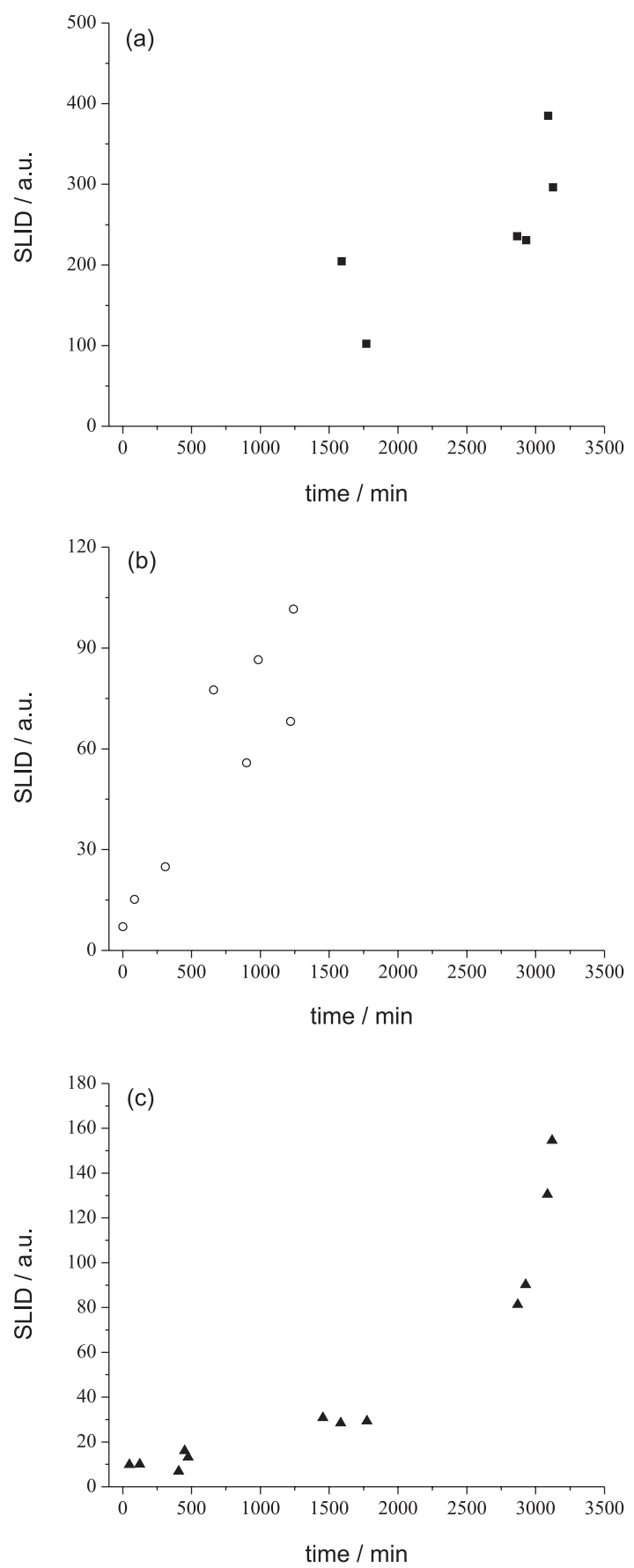

Figure 2. Variation of the scattered light intensity (SLID) with synthesis time during the first step of (a) C60S0, (b) C60SB and (c) C60SA.

smaller particles (ca. $100 \mathrm{~nm}$ ) accompanying the $5 \mu \mathrm{m}$ particles appear at longer times. The smallest particles (ca. $100 \mathrm{~nm}$ ) are formed by aggregation of even smaller particles (not seen by DLS) and rapidly aggregate into larger particles $(5 \mu \mathrm{m})$. Both kind of particles $(100 \mathrm{~nm}$ and $5 \mu \mathrm{m})$ are seen by DLS only when the observation time coincides or is close to the appearance of the two phenomena. The described aggregation seems to be a continuous process during the synthesis.
Now, that it is known that the polymeric resin can form particles at the synthesis conditions, without the addition of surfactant, it is necessary to reconsider the results of DLS measurements for C60SB and C60SA. These materials at the flocculation can be formed by resol nanoparticles (100\% phenolic resin) and by micelles covered by resol species (hybrid micelles). The observed abrupt change in the Dh during first synthesis step for these two materials can be attributed not only to the covering of the micelles but also to the formation of resin particles. A shorter time for the aggregation of such combined particles in C60SB than in C60SA is also explained by a higher contribution of resin particles in the flocculation of C60SB. This is in agreement with the flocculation time presented for the C60S0 solution, which corresponds only to the formation of resol particles.

By comparing the change in the scattered light intensity (Figure 2) for the three materials, interesting features are revealed. Before the flocculation, a steeper change in scattering intensity for C60SB (when compared with C60SA) indicates that there is a higher covering of the micelles for C60SB due to the lower amount of micelles to be covered. On the other hand, around the flocculation time for C60SB, the change in scattering intensity is fluctuating and less steep than for C60SA. This can be due to a flocculation of a colloidal suspension formed with a more important contribution of resin nanoparticles than in the case of C60SA. This conclusion is supported by the fact that the changes in the scattering intensity around the flocculation time for C60S0 (in which there are not micelles and only phenolic resin nanoparticles can be formed) have similar features to that of C60SB. In conclusion, higher surfactant concentration of C60SA allows a more homogenous phase separation (with a flocculation mainly represented by hybrid nanoparticles) and therefore can lead to more mesoporous organized materials. The nature of this phase is fluid, since no cloudiness is observed, so the conditions of polycondensation during aging are very crucial to determine the properties of the final polymers or obtained carbons.

\section{Porous and thermal characteristics of C60S0, C60SB and} C60SA materials

After carbonization of the synthesized resols, the porous characteristics of the C60SA, C60SB and C60S0 materials were analyzed by $\mathrm{N}_{2}$ sorption at $77 \mathrm{~K}$.

The isotherm for C60S0 (Figure 3c) is typical of a nonporous material, showing that the carbonization process and the liberation of gases do not confer to the material any "intrinsic" porosity, at least in the measured mesoporous range available by the nitrogen adsorption 

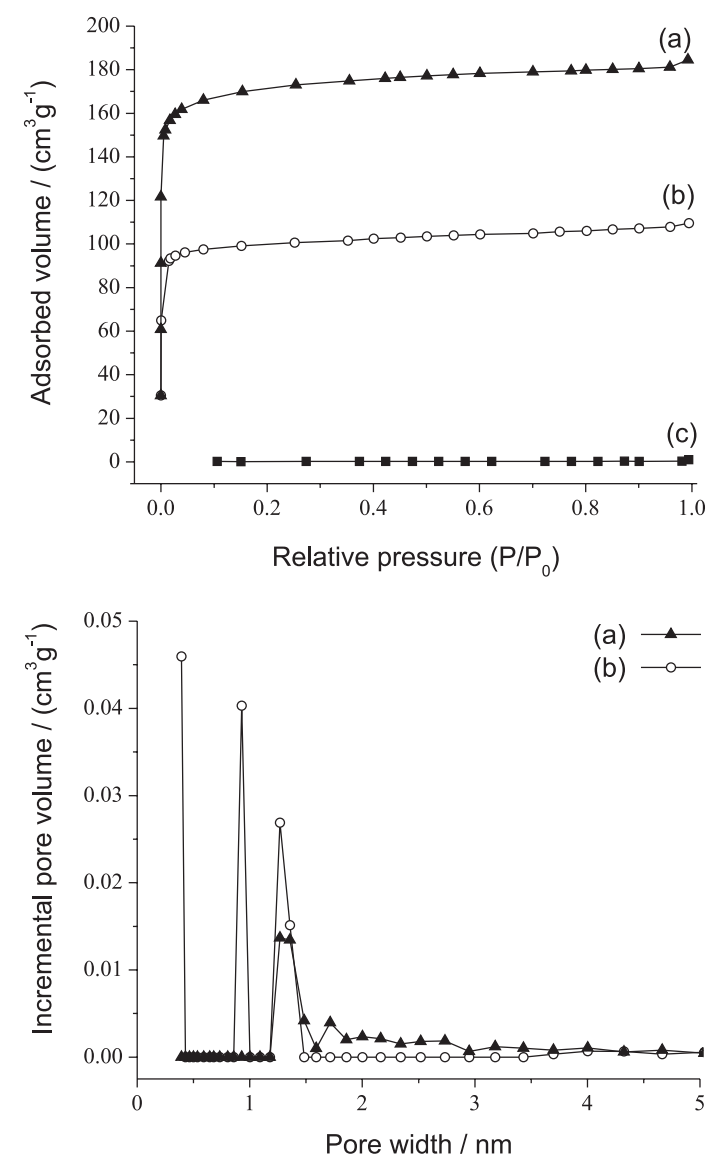

Figure 3. $\mathrm{N}_{2}$ adsorption isotherms and DFT pore size distributions of (a) C60SA, (b) C60SB and (c) C60S0.

technique. It was expected some textural porosity in this material,,$^{14}$ but since in this case the size of the particles formed is $>1 \mu \mathrm{m}$, only macroporosity can be formed. The macroporosity is not observed due to the limitation of the nitrogen adsorption technique (with an observable pore size in the range $0.8-200 \mathrm{~nm}$ ).

The nitrogen adsorption isotherms for the C60SB and C60SA (Figure $3 \mathrm{a}$ and $3 \mathrm{~b}$ ) are of type I, typical of microporous materials. Table 2 describes the porous characteristics of these materials in terms of total, microporous and mesoporous volume. The formation of these porosities takes place due to the presence of surfactant in the synthesis reaction. The reasosns for this are that no microporosity was seen in C60S0 material and that the porosity increases as the surfactant concentration in the synthesis mixture increases.

It is interesting to realize that the mesoporosity in these materials is very low even though the method of adopted synthesis is a method for obtaining mesoporous carbons in alkaline medium ${ }^{10}$ by using the Pluronic ${ }^{\circledR}$ F127 surfactant as template. This behavior must be related to the replacement of the Pluronic ${ }^{\circledast}$ F127 surfactant by a Pluronic ${ }^{\circledR}$ surfactant with longer hydrophilic chains which can provoke a different micelle behavior, for instance: (i) disruption of the hybrid micelles during the hydrothermal treatment (decrease of the hybrid nanoparticle population) or carbonization process and (ii) excessive shrinking of the polymer framework during the carbonization process causing a large decrease in the pore size.

The interesting aspect to point out is that the increase in surfactant concentration shows a marked tendency of increasing both the micro and mesoporosity. Moreover, the polymerization degree of the resol in the hybrid micelles is another important factor that influences the obtaining of a mesostructure with the qualities to produce a highly organized mesoporous material.

\section{Effects of the synthesis temperature and resol prepolimerization step}

\section{Synthesis and characterization of C80SA and C80SA-NP}

C80SA and C80SA-NP materials were synthesized at $80{ }^{\circ} \mathrm{C}$ with the same composition of C60SA, with and without the prepolymerization step, respectively. In the synthesis of C80SA, a light brown particulate solid was recovered. Whereas in the synthesis of C80SA-NP, a dark red monolithic material (C80SA-NPR) was formed in the bottom of the flask and over this a light brown particulate solid like that one in C80SA was deposited (C80SA-NPB).

The obtaining of the two different materials in the C80SA-NP synthesis is another indicative of the presence of a competitive mechanism, which is further supported by the porous characteristics of these two materials. The nitrogen adsorption isotherms of the three materials synthesized at $80{ }^{\circ} \mathrm{C}$ are shown in Figure 4. C80SA-NPR

Table 2. Porous characteristics of C60S0, C60SA and C60SB

\begin{tabular}{lccccc}
\hline Material & $\mathrm{V}_{\mathrm{p}}{ }^{\mathrm{a}} /\left(\mathrm{cm}^{3} \mathrm{~g}^{-1}\right)$ & $\mathrm{V}_{\text {micropore }} /\left(\mathrm{cm}^{3} \mathrm{~g}^{-1}\right)$ & $\mathrm{V}_{\text {mesopore }} /\left(\mathrm{cm}^{3} \mathrm{~g}^{-1}\right)$ & $\mathrm{S}_{\mathrm{BET}}{ }^{\mathrm{d}} /\left(\mathrm{m}^{2} \mathrm{~g}^{-1}\right)$ & $\mathrm{D}$ \\
\hline C60S0 & 0.00 & 0.00 & N.A & 0.5 & N.A. \\
C60SB & 0.17 & 0.16 & 0.01 & 324.4 & $0.9-1.3$ \\
C60SA & 0.29 & 0.27 & 0.02 & 558.1 & 1.3 \\
\hline
\end{tabular}

${ }^{a}$ Total volume at $\mathrm{P} / \mathrm{P}_{0}=0.9941 ;{ }^{\mathrm{b}} \alpha_{\mathrm{s}}$-plot micropore volume (using a nonmicroporous carbon reference) $;{ }^{15} \mathrm{c}$ mesoporous volume; ${ }^{\mathrm{d} B E T}$ specific surface area; emicropore diameter (DFT theory). 

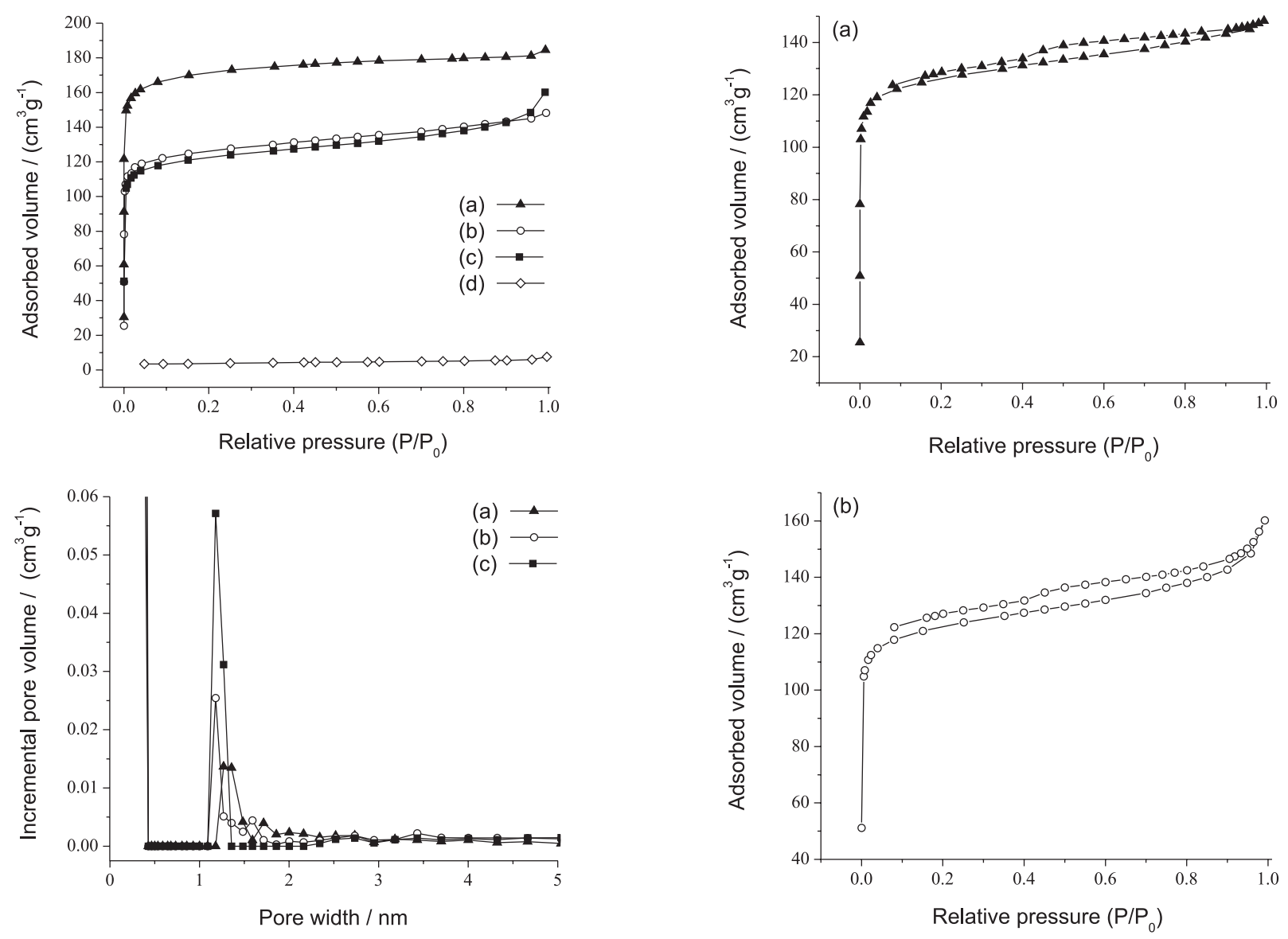

Figure 4. $\mathrm{N}_{2}$ adsorption isotherms and DFT pore size distributions of (a) C60SA, (b) C80SA, (c) C80SA-NPB and (d) C80SA-NPR.

does not show any porosity and has a similar behavior of the material synthesized at $60{ }^{\circ} \mathrm{C}$ without surfactant (C60S0). On the other hand, C80SA-NPB shows an isotherm of type IV (Figure 4 and 5a) with a higher mesoporous character (Table 3 ) than that found for the materials synthesized at $60^{\circ} \mathrm{C}$. Probably the material C80SA-NPB is formed by a mechanism of covering of the micelles. But due to a shrinking of the polymer structure during the hydrothermal treatment and carbonization process, micropores are formed. In contrast, C80SA-NPR is formed by the aggregation of resol particles like C60S0, and does not present any microporosity.

Figure 5. $\mathrm{N}_{2}$ adsorption-desorption isotherms of (a) C80SA and (b) C80SA-NPB.

C80SA material also shows an isotherm of type IV (Figure 4 and 5a), with some mesoporous character and a substantial specific surface area $\left(413 \mathrm{~m}^{2} \mathrm{~g}^{-1}\right)$. Probably this material is formed by the micelle covering mechanism rather than by the resol particle one. The effect of doing the synthesis with the monomers instead of the oligomers at the conditions of this work was to favor the resin particles formation mechanism (C80SA-NPR). But, at the same time, the interaction between the monomers and surfactant is apparently more appropriate to form stable hybrid micelles because the C80SA-NPB material presents higher mesoporous and total porous volume.

Table 3. Porous characteristics of C60SA, C80SA, C80SA-NPB and C80SA-NPR

\begin{tabular}{|c|c|c|c|c|c|}
\hline Material & $\mathrm{V}_{\mathrm{p}}{ }^{\mathrm{a}} /\left(\mathrm{cm}^{3} \mathrm{~g}^{-1}\right)$ & $\mathrm{V}_{\text {micropore }} \mathrm{b} /\left(\mathrm{cm}^{3} \mathrm{~g}^{-1}\right)$ & $\mathrm{V}_{\text {mesopore }} \mathrm{c} /\left(\mathrm{cm}^{3} \mathrm{~g}^{-1}\right)$ & $\mathrm{S}_{\mathrm{BET}}{ }^{\mathrm{d}} /\left(\mathrm{m}^{2} \mathrm{~g}^{-1}\right)$ & $\mathrm{D}^{\mathrm{e}} / \mathrm{nm}$ \\
\hline C60SA & 0.29 & 0.27 & 0.09 & 558.1 & 1.3 \\
\hline C80SA & 0.23 & 0.20 & 0.03 & 413.14 & 1.2 \\
\hline C80SA-NPB & 0.27 & 0.19 & 0.08 & 445.27 & $0.73-1.3$ \\
\hline C80SA-NPR & 0.01 & 0.00 & 0.01 & 12.64 & N.A. \\
\hline
\end{tabular}

${ }^{\mathrm{a}}$ Total volume at $\mathrm{P} / \mathrm{P}_{0}=0.9941 ;{ }^{\mathrm{b}} \alpha_{\mathrm{s}}$-plot micropore volume (using a nonmicroporous carbon reference) ${ }^{15}$; ${ }^{\mathrm{c}}$ mesoporous volume; ${ }^{\mathrm{d}} \mathrm{BET}$ specific surface area; ${ }^{\mathrm{e}}$ micropore diameter (DFT theory). 
The synthesis temperature effect can be seen comparing the porous characteristics between C60SA and C80SA, both prepared with the prepolymerization step (Figure 4 and Table 3). C60SA exhibited a higher porous volume and a higher specific surface area than C80SA (although this volume and area come mainly from micropores) (Table 3). This means that a higher synthesis temperature makes the covering process more suitable for the formation of mesoporosity. But once again, the carbonization process can cause an excessive shrinking and a partial disruption of the formed mesoporosity. In other words, the obtained covering under the reaction system composition of this work at $80{ }^{\circ} \mathrm{C}$ is not still the optimum to get a highly mesoporous carbon.

\section{FTIR analysis}

The FTIR spectra of R60SA and R60S0 are shown in Figure 6. All materials synthesized in the presence of the surfactant showed a FTIR spectrum similar to that the one presented by R60SA, therefore their spectra are not presented. The characteristic bands for a resol type phenolic resin ${ }^{16-18}$ are seen for R60S0 (Figure 6a): the $\mathrm{O}-\mathrm{H}$ stretching band due to the phenol group at $3317 \mathrm{~cm}^{-1}$, the aromatic $=\mathrm{C}-\mathrm{H}$ and $\mathrm{C}=\mathrm{C}$ aromatic stretching at 3008 and $1598 \mathrm{~cm}^{-1}$, respectively. The low intensity in the $=\mathrm{C}-\mathrm{H}$ stretching is due to a high substitution of the aromatic rings. The bands between 2800 and $3000 \mathrm{~cm}^{-1}$ are due to the stretching of $\mathrm{CH}_{2}$ saturated bonds, whose presence as methylene bonds of the resin is also confirmed by the band at $1477 \mathrm{~cm}^{-1}$. The band at $1014 \mathrm{~cm}^{-1}$ is characteristic for the methylol bridges of the resin.

Looking at the FTIR spectrum of R60SA, it is possible to observe that the interaction between the surfactant and the phenolic resin has some effects in the frequencies of some bands. The aromatic $\mathrm{C}=\mathrm{C}$ stretching band appears with a

Table 4. TGA (in air) results for the different materials
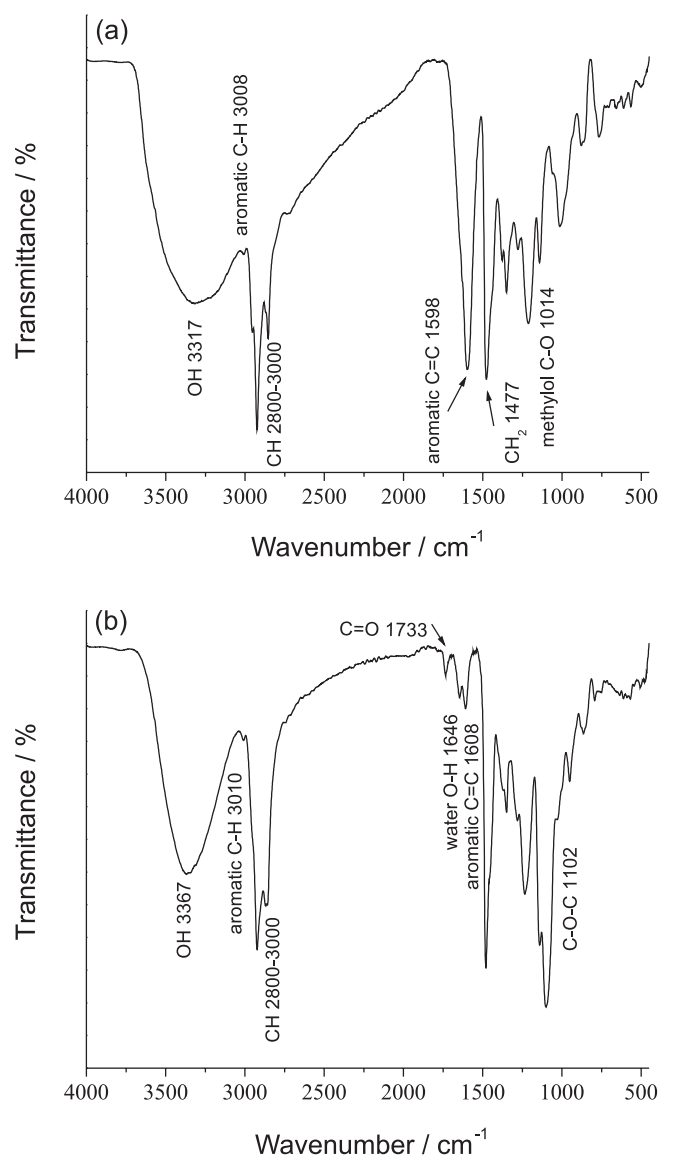

Figure 6. FTIR spectra of (a) R60S0 and (b) R60SA.

lower intensity probably due to the high mass content of surfactant (Table 4). Moreover, it is also shifted to a higher wavenumber (from 1598 to $1608 \mathrm{~cm}^{-1}$ ). Furthermore, two new bands appear at 1733 and $1646 \mathrm{~cm}^{-1}$ that correspond to $\mathrm{C}=\mathrm{O}$ stretching of the residual formaldehyde ${ }^{16}$ and to the $\mathrm{H}-\mathrm{O}-\mathrm{H}$ stretching of water, respectively. The presence of water could be attributed to a more hydrophilic behavior of the materials conferred by the surfactant and the presence

\begin{tabular}{|c|c|c|c|c|}
\hline Material & $\begin{array}{c}\text { First weight } \\
\operatorname{loss}^{\mathrm{a}} / \%\end{array}$ & $\begin{array}{c}\text { Second weight } \\
\operatorname{loss}^{\mathrm{b}} / \%\end{array}$ & $\begin{array}{l}\text { First weight loss } \\
\text { temperature } /{ }^{\circ} \mathrm{C}\end{array}$ & $\begin{array}{c}\text { Second weight loss } \\
\text { temperature } /{ }^{\circ} \mathrm{C}\end{array}$ \\
\hline R60S0 & 28.69 & 65.34 & N.A. & 587.8 \\
\hline R60SB & 45.57 & 53.26 & 328.5 & 424.6 \\
\hline R60SA & 46.21 & 52.60 & 320.8 & 466.1 \\
\hline C60S0 & 14.20 & 72.54 & $409.6^{c}$ & $599.8^{\mathrm{c}}$ \\
\hline C60SB & 96.50 & N.A. & 400.1 & N.A. \\
\hline C60SA & 98.51 & N.A. & 457.3 & N.A. \\
\hline C80SA & 97.72 & N.A. & 421.2 & N.A. \\
\hline C80SA-NPB & 97.46 & N.A. & 411.8 & N.A. \\
\hline C80SA-NPR & 36.97 & 59.55 & $448.8^{c}$ & $614.4^{\mathrm{c}}$ \\
\hline
\end{tabular}

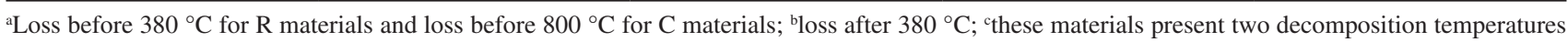
between $380-700{ }^{\circ}$ C; N.A.: it does not apply. 
of residual formaldehyde to a lower polymerization rate due also to the presence of the triblock surfactant.

\section{TGA analysis}

Figure 7 shows the TGA graphs for the resol materials synthesized at $60^{\circ} \mathrm{C}$ and for all carbon materials. The R60S0 material (Figure 7a) presents a typical thermogram for a cured phenolic resin. ${ }^{19}$ The weight losses in the $100-300{ }^{\circ} \mathrm{C}$ range are due to entrapped solvent, water from methylol
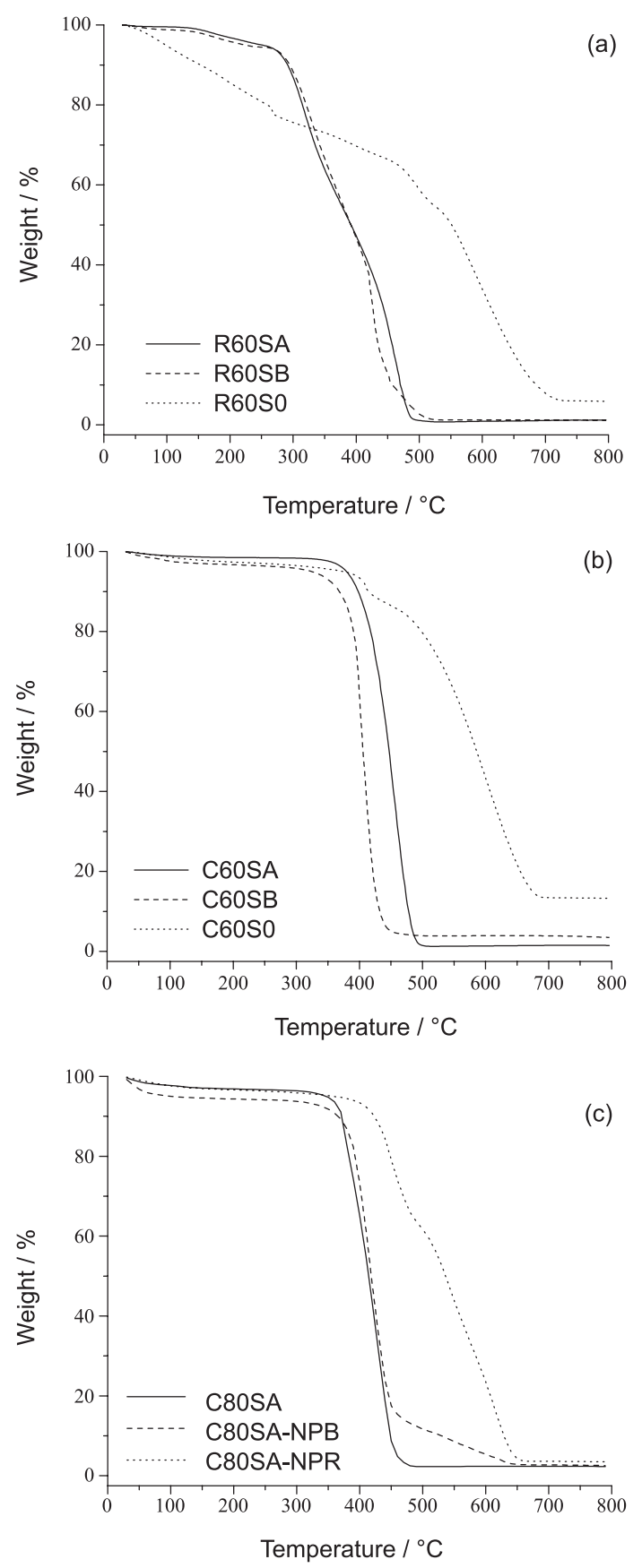

Figure 7. TGA thermographs in air of (a) resol materials synthesized at $60{ }^{\circ} \mathrm{C}$, (b) carbon materials synthesized at $60^{\circ} \mathrm{C}$ and (c) carbon materials synthesized at $80^{\circ} \mathrm{C}$. condensation and low molecular weight components. These weight losses depend on the formaldehyde to phenol mole ratio and the curing degree of the resins. The large loss in this temperature range that is seen for R60S0 (22\%) is consistent with the low formaldehyde to phenol ratio and the relative low synthesis temperature. The weights losses between 300 and $400^{\circ} \mathrm{C}$ are due to a post-curing process and those ones at higher temperatures (maximum $c a .588{ }^{\circ} \mathrm{C}$ ) are attributed to the thermal decomposition of the material.

It is observed a different behavior for R60SB and R60SA compared with R60S0. Before $300{ }^{\circ} \mathrm{C}$, they present a smaller weight loss (around 10\%), and in the $300-400{ }^{\circ} \mathrm{C}$ range a steeper loss due to the decomposition of the surfactant ${ }^{10}$ and the post-cure process of the resol. These materials practically do not present weight losses at higher temperatures than $400{ }^{\circ} \mathrm{C}$ as R60S0 does.

The decomposition temperatures for R60SB and R60SA materials are lower than for the material R60S0 probably due to modification of the resin polymerization and crosslinking degree caused by the presence of the surfactant. Hong et al. ${ }^{20}$ showed that different modifications on the resol structure can improve the decomposition temperature (silicon modified resins, boron-phosphorous modified resins). In our case, the surfactant seems to interact with the polymeric structure, decreasing its decomposition temperature. This effect is more important in R60SB, which was prepared with lower amount of surfactant and showed less mesoporous character, since it presents the second decomposition step at lower temperature than R60SA.

The carbon materials prepared in the presence of surfactant also show lower decomposition temperatures than C60S0. Again, this temperature for the material C60SB is lower than for the material C60SA, indicating that the structural effects occasioned by the interaction of the surfactant and the polymer also take place in the final derived carbon.

It is interesting to notice that not only the surfactant concentration but the synthesis temperature and the prepolymerization step also play a critical role on this decomposition temperature and therefore, in the final polymer and carbon structures. Comparing the three materials that afforded better porosity (C60SA, C80SA and C80SA-NPB), the material C80SA synthesized at $80{ }^{\circ} \mathrm{C}$ exhibited lower decomposition temperature than C60SA synthesized at $60^{\circ} \mathrm{C}$, but higher than C80SA-NPB, also synthesized at $80^{\circ} \mathrm{C}$ without prepolymerization step. Apparently the crosslinking or polymerization degree of the resin (which is modified by the concentration of the surfactant and the presence of resin monomers or oligomers in the reaction mixture and the temperature) must be low to obtain mesoporous carbons instead of non-porous carbons. 

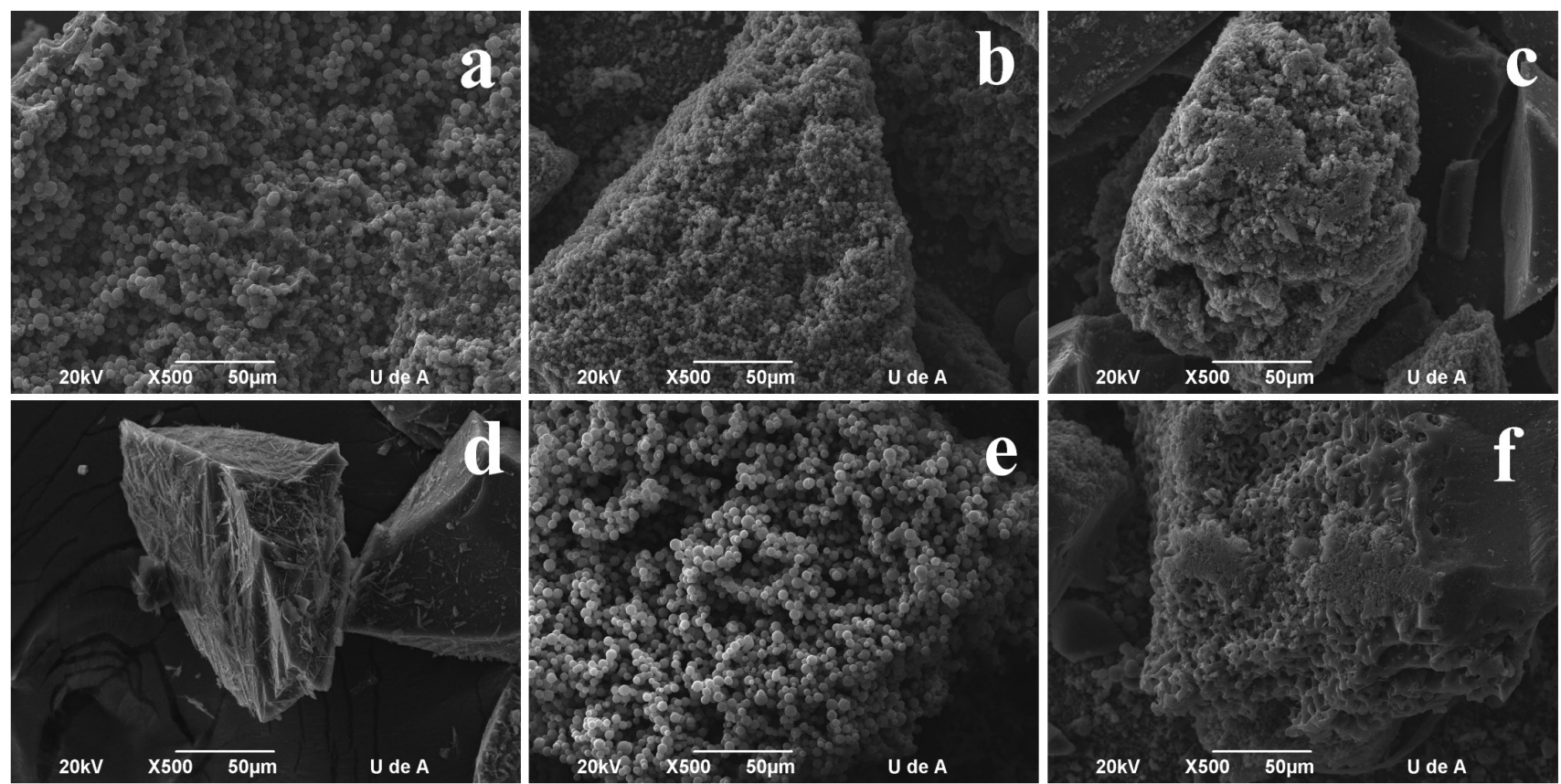

Figure 8. SEM images of (a) C80SA, (b) C80SA-NPB, (c) C80SA-NPR, (d) C60S0, (e) C60SA and (f) C60SB.

Additionally, the TGA results for the two materials synthetized at $80^{\circ} \mathrm{C}$ without the prepolymerization step evidence the presence of the two mechanisms described before. C80SA-NPB was formed from the aggregation of hybrid micelles since only a decomposition temperature is seen in this case. C80SA-NPR was formed by a mechanism of primary polymer particle formation, since two decomposition temperatures are observed, similarly to C60S0.

\section{Materials morphology}

Scanning electron microscopy (SEM) was used to characterize and compare the morphology of all materials with the images shown in Figure 8.

C60SA looks as formed by aggregation of spherical particles with sizes $<10 \mu \mathrm{m}$. The coalescence of these particles is not so high. C60SB (with a lower surfactant concentration than C60SA) presents monolithic type morphology. This morphology is very similar to the one presented by C60S0, which was synthesized without the presence of surfactant. The similarities between the morphologies for this two materials support the DLS results. C60S0 and C60SB with shorter flocculation times exhibit a monolithic morphology. Meanwhile C60SA with a higher flocculation time presents a particle-like morphology.

For materials obtained at $80^{\circ} \mathrm{C}$, similar morphologies are observed. C80SA and C80SA-NPB are composed by the aggregation of spherical particles with sizes between 2 and $10 \mu \mathrm{m}$, whose morphology is analogous to the
C60SA one. On the other hand, the C80SA-NPR material exhibits monolithic morphology such as the C60S0 and C60SB materials. These results also support the presence of two competitive mechanisms in the synthesis of carbon materials, whose relative occurrence highly depends on the surfactant concentration and the use of monomers or oligomers as precursors in the synthesis. Indeed, the observed morphologies for all materials depend strongly on the mechanism followed to form these materials. If the micelles covering mechanism is mainly present, materials formed by the aggregation of spherical particles are obtained. On the contrary, if resol particles are mainly formed, the final materials will have monolithic morphologies.

\section{Conclusions}

Experimental evidence (by DLS, nitrogen adsorption, FTIR spectra, SEM images and TGA data) is provided in this work for supporting that in the synthesis of porous carbons by direct soft-templating method (in aqueous alkaline medium, employing the triblock copolymer surfactant $\mathrm{PEO}_{140} \mathrm{PPO}_{39} \mathrm{PEO}_{140}$ ), a competitive mechanism of the formation of the resol particles takes place. It was reconfirmed that DLS is a valuable tool for monitoring the synthesis of porous materials obtained by softtemplating approaches. According to DLS, at $60{ }^{\circ} \mathrm{C}$ under the synthesis conditions of this work, the formation of covered hybrid micelles (before flocculation) for obtaining porous materials and therefore the competence of this 
mechanism with the formation of resol particles depends on the surfactant concentration. Higher concentration of the surfactant (S14600: $\mathrm{NaOH}: \mathrm{H}_{2} \mathrm{O}$ molar ratio of 1:15:16900) favors the formation of hybrid micelles whereas the lower one (S14600: $\mathrm{NaOH}: \mathrm{H}_{2} \mathrm{O}$ of $\left.0.33: 15: 16900\right)$ does not. By TGA analysis, it can be deduced that the synthesis temperature and the nature of the resin precursor species (monomers versus oligomers) also play an important role. A synthesis temperature of $80{ }^{\circ} \mathrm{C}$ with the higher surfactant concentration increases the yield of mesoporous carbon. This increase is even better when monomers instead of oligomers are used as resin precursors but the formation of resol particles is also favored. Appropriate interaction between surfactant/resin precursor species and polycondensation or crosslinking degree of these covering resin species seems to be crucial for obtaining mesoporous carbons. According to the range of studied conditions in this work, it is possible to conclude that $\mathrm{S} 14600: \mathrm{H}_{2} \mathrm{O}$ molar ratio higher than 0.33:16900 at $\mathrm{pH} 9.4$, synthesis temperature higher than $60{ }^{\circ} \mathrm{C}$ and the use of monomers can conduce to better mesoporous carbons.

\section{Acknowledgments}

The authors wish to thank to Programa de Sostenibilidad 2009-2010 of the Universidad de Antioquia (Medellín, Colombia) for the financial support. Cristiam F. Santa gratefully acknowledge to CODI for the Jovenes Investigadores internship.

\section{References}

1. Corma, A.; Chem. Rev. 1997, 97, 2373.

2. Barrer, R.; Hydrothermal Chemistry of Zeolites; Academic Press: London, 1982.

3. Ding, S.; Jianghua, Z.; Jingxing, C.; Yingliang, L.; Int. J. Electrochem. Sci. 2009, 4, 9.
4. Huo, Q.; Margolese, D.; Ciesla, U.; Feng, P.; Gier, T. E.; Sieger, P.; Leon, R.; Petroff, P.; Schuth, F.; Stucky, G.; Nature 1994, 368, 317.

5. Liang, C.; Hong, K.; Guiochon, G.; Mays, J.; Dai, S.; Angew. Chem., Int. Ed. 2004, 43, 5785.

6. Liang, C.; Dai, S.; J. Am. Chem. Soc. 2006, 128, 5316.

7. Tanaka, S.; Nishiyama, N.; Egashira, Y.; Ueyama, K.; Chem. Commun. 2005, 2125.

8. Kosonen, H.; Valkama, S.; Nykänen, A.; Toivanen, M.; Ten Brinke, G.; Ruokolainen, J.; Ikkala, O.; Adv. Mater. 2006, $18,201$.

9. Meng, Y.; Gu, D.; Zhang, F.; Shi, Y.; Yang, H.; Li, Z.; Yu, C.; Tu, B.; Zhao, D.; Angew. Chem., Int. Ed. 2005, 44, 7053.

10. Meng, Y.; Gu, D.; Zhang, F.; Shi, Y.; Cheng, L.; Feng, D.; Wu, Z.; Chen, Z.; Wan, Y.; Stein, A.; Zhao, D.; Chem. Mater. 2006, 18, 4447.

11. Sierra, L.; Valange, S.; Barrault, J.; Guth, J.; Microporous Mesoporous Mater. 2008, 113, 352.

12. Mesa, M.; Sierra, L.; Guth, J.; Microporous Mesoporous Mater. 2008, 112, 338.

13. Sierra, L.; Valange, S.; Guth, J.; Microporous Mesoporous Mater. 2009, 124, 100.

14. Scherdel, C.; Scherb, T.; Reichenauer, G.; Carbon. 2009, 47, 2244.

15. Rodriguez-Reinoso, F.; Martin-Martinez, J.; Prado-Burguete, C.; McEnaney, B.; J. Phys. Chem. 1987, 91, 515.

16. Holopainen, T.; Alvila, L.; Rainio, J.; Pakkanen, T.; J. Appl. Polym. Sci. 1998, 69, 2175.

17. Poljanšek, I.; Šebenik, U.; Krajnc, M.; J. Appl. Polym. Sci. 2006, 99, 2016.

18. Nagy, D. In Phenolic Resins: a Century of Progress, vol. 1; Pilato, L., ed.; Springer, Bound Brook: New Jersey, 2010.

19. Lochte, H.; Strauss, E.; Conley, R.; J. Appl. Polym. Sci. 1965, 9, 2799.

20. Hong, U.; Jung, S.; Cho, K.; Cho, M.; Kim, S.; Jang, H.; Wear 2009, 266, 739. 